\title{
Virtual Exercisers and Simulators as a Part of an Online Education
}

\section{NatalyaO.Gordeeva}

Belgorod State University, Stary Oskol branch,Russia 309502, Stary Oskol, Solnechny micro-district., 18.
Study Area/ Coordination:

Key words: Professional education, Online course elements,

functional purpose, basic characteristics, rules and procedures for conformity assessment are defined in the corresponding GOST R 53626-2009 (http://docs.cntd.ru/ document/1200o80386). "Information and communication technologies in education. Technical training aids" (Björn et al., 2020).

Initially, the simulators were aimed at forming professional skills of adult qualified employees and were used for practicing error-free actions as a prerequisite for gaining access to a workplace. The second wave of simulators was related to mastering computer skills. As an example, there are various types of keyboard simulators, the purpose of which is to form the skills of working witha keyboard. At the beginning of the XXI century, the development of modern educational and information technologies, and the provisions of practice-oriented learning became a prerequisite for a wider use of exercisers and simulators in vocational training.

Simulators are simulation software systems that represent some aspect of the real world to study its basic structural or functional characteristics using a limited number of parameters (Reddin et al., 2021). Virtual exercisers and simulators together provide students with a specific production environment in which a particular situation can be played out.

The pedagogical impact of such systems is revealed in the possibility to develop with their help the ability to independently transfer the learned knowledge to a new situation, to see a new function of the known object, to see options for methods of solving the problem set. It is reasonable to develop their own concept, methodology and algorithms for using exercisers and simulators as part of implementing an educational program in a particular field of training.

However, most teachers note that, regardless of the specialization, the use of simulation environments ensures the implementation of a set of methodological objectives:

- Provides an opportunity for practical illustrating the theoretical concepts of the course;

* Increases students' interest and involvement;

* Increases the level of students' knowledge, decision-making, and teamwork experience;

* Provides a tool for testing students' practical skills and strategic thinking. 
* Allows the teacher to manage the sequence of the course in any format (in-class, online, or combined).

The use of simulators opens up a number of additional possibilities that are not available in a traditional hands-on training environment (Shorey \& Ng, 2021). An instructor can slow down the progress towards resolving a production task using a simulator or even stop the task by discussing its progress and possible scenarios for the activities of the participants. Training with the use of a simulator makes it possible to change the parameters of training situations, providing targeted training of individual skills tailored to the characteristics of the trainees. The training system records everything that happens during a lesson and accumulates data on the actions of students, providing rich material for subsequent analysis and evaluation of educational results (Jasti et al., 2020).

Ouranalysis:

The key idea of distance and online learning is based on active independent forms of acquiring knowledge and working with information. The most important condition for the effectiveness of such training is the student's independence and activity, the ability to organize their own activities (self-directed learning), skills of conscious and responsible solution of professional problems. Virtual exercisers can be used for different purposes at different points in an online course. The key question of when to use an exerciser is the extent to which students' prior knowledge is critical to be successful when passing the exercise.

At the beginning of a course, exercisers can contribute to the development of an effective learning community. The exerciser can be used to help students connect course ideas and concepts by clarifying connections between different aspects of their mastery. This should help them understand the interconnected nature of the theoretical statements.

At the next stage, participation in the simulation helps to develop higher-level cognitive skills such as analysis and evaluation, where participants are encouraged their knowledge and skills gained as a result of the simulation to apply to the business and its future activities.

In order to use the virtual environment potential effectively, trainees need to be provided with an appropriate methodological framework from which an individual trajectory should be planned. On the basis of his/her experience, the teacher (tutor) must decide how much guidance to give students in each of the proposed tasks. It is the tutor who finds the balance between providing sufficient guidance to ensure the success of the assignment and giving students sufficient opportunity to develop their own ideas and work independently. The task of finding such a balance is not trivial, as less capable students can easily get lost in the vast amount of material without a clear and detailed algorithm, and overly detailed guidelines for orienting between more and less relevant information and for course planning can deny students the opportunity to work independently. Clear and non-redundant guidelines are critical to achieving the goals of using a simulation environment. The following principles for the preparation of methodological recommendations accompanying the use of exercisers and simulators as part of an online course can beproposed.

First of all, the main stages of the tasks and the criteria that will be used in the evaluation should be described.

It is important that students be able to understand the general idea and structure of the simulation and clearly understand its goals for learning. Guidelines may take the form of identifying key aspects of the assignments or describing role profiles if the simulation involves different levels of participation. The specific details included in the guidelines may vary depending on the students' prior training and skills, as well as their familiarity with this mode of operation.

Regard is to be had that each trainee in an online course may approach the simulator tasks differently, and this should be reflected in the development of a grading system that adequately compares the quality of their work. As the experience of using business simulations shows, an effective grading system is the one modified on the basis of students' feedback on the difficulty of performing certain tasks obtained during the experimental operation of a virtual environment.

Methods of using simulators and exercisers are advisable to focus on the formation of skills of independent acquisition, presentation, and demonstration of skills.

\section{References:}

Björn, M.H., Laurila, J.M., Ravyse, W., Kukkonen, J., Leivo, S., Mäkitalo, K. \& Keinonen, T. (2020): Learning impact of a virtual brain electrical activity simulator among neurophysiology students: mixed-methods intervention study. JMIR Ser. Game., 8(4):e18768.

Guzmán, J.L. \& Joseph, B. (2021): Web-based virtual lab for learning design, operation, control, and optimization of an anaerobic digestion process. J. Sci. Edu. Tech., 30(3):319-330.

Jasti, N.V., Kota, S. \& Venkataraman, P.B. (2020): Development of a lean manufacturing simulation laboratory for continuing education students. J. Adult Cont. Edu., 1477971420962519.

Pirola, C., Peretti, C. \& Galli, F. (2020). Immersive virtual crude distillation unit learning experience: The EYE4EDU project. Comp. Chem. Engineer., 140:106973.

Reddin, K., Bang, H. \& Miles, L. (2021). Evaluating simulations as preparation for health crises like CoVID-19: Insights on incorporating simulation exercises for effective response. Int.J. Disaster Risk Reduc., 59:102245.

Shorey, S. \& Ng, E.D. (2021): The use of virtual reality simulation among nursing students and registered nurses: A systematic review. Nurse Edu. Today, 98:104662.

Worrall, A.F., Bergstrom Mann, P.E., Young, D., Wormald, M.R., Cahill, S.T., \& Stewart, M.I. (2020): Benefits of Simulations as Remote Exercises During the COVID-19 Pandemic: An Enzyme Kinetics Case Study. J. Chem. Edu., 97(9):2733-2737. 